\title{
RANCANGAN SISTEM INFORMASI LOGISTIK KEBENCANAAN STUDI KASUS: BADAN PENANGGULANGAN BENCANA DAERAH JAWA BARAT
}

\author{
${ }^{1}$ Alfaidzah Ummal, ${ }^{2}$ Djaka Dito Wicaksana \\ ${ }^{1,2}$ Program Studi D-III Manajemen Informatika, Politeknik Pos Indonesia \\ Email: ${ }^{1}$ alfaidzah.umma105@gmail.com, ${ }^{2}$ djakadito@gmail.com
}

DOI: https://doi.org/10.46880/jmika.Vol4No1.pp37-42

\begin{abstract}
ABSTRAK
Badan Penanggulangan Bencana Daerah sebagai instansi yang bergerak terhadap penanggulangan bencana alam memiliki departemen yang mengoordinir bantuan logistik para korban bencana alam yaitu Bagian Logistik Kebencanaan yang bertanggung jawab terhadap semua bantuan logistik baik yang ada di gudang maupun yang akan disalurkan kepada korban bencana. Dalam penelitian ini pengamatan proses bisnis dilakukan di Badan Penanggulangan Bencana Daerah Jawa barat mengalami bisnis proses mulai dari pendataan kebutuhan bantuan logistik, koordinir bantuan logistik yang ada di gudang, pendistribusian bantuan logistik sampai ke posko bencana sampai pada tahapan pelaporan. Pada saat melakukan pendataan kebutuhan, pencatatan barang bantuan logistik yang ada digudang dan pelaporan dari pihak instansi masih menggunakan sistem lembar kerja yang memungkinkan terjadi nya kesalahan dalam proses transaksi. Serta sistem pendistribusian bantuan logistik ke posko bencana yang masih kurang efisien karna kurangnya analisis terhadap tingkat kebutuhan para korban bencana. Berdasarkan kebutuhan ini, diperlukan desain aplikasi Sistem Informasi Logistik Kebencanaan di Badan Penanggulangan Bencana Daerah Jawa Barat yang memiliki kemampuan fungsional untuk mengelola data kebutuhan bantuan logistik, mengelola bantuan logistik yang ada di gudang, serta memudahkan dalam analisis pendistribusian bantuan logistik. Dalam tahapan analisis pemodelan menggunakan Business Process Modeling Notation (BPMN), sedangkan tahapan perancangan menggunakan Unified Modeling Language (UML). Desain aplikasi ini akan menjadi pedoman dalam mengimplementasikan perangkat lunak pada penelitian selanjutnya.
\end{abstract}

Kata Kunci: Rancangan, Aplikasi, Logistik, BPMN, UML

\section{PENDAHULUAN}

Dalam suatu instansi, sistem informasi manajemen sangat membantu kinerja perusahaan agar lebih efektif dan efisien. Seperti hal nya mengelola bantuan logistik bencana alam untuk para korban bencana alam. Instansi pemerintah yang bertanggung jawab dalam hal penanggulangan bencana adalah Badan Nasional Penanggulangan Bencana (BNPB). Sedangkan Badan Penanggulangan Bencana Daerah (BPBD) Provinsi Jawa Barat merupakan lembaga penanggulangan bencana yang berkedudukan di bawah dan bertanggung jawab kepada Gubernur.

Dalam menyelenggarakan tugas pokok tersebut Badan Penanggulangan Bencana Daerah Provinsi Jawa Barat mempunyai fungsi sebagai berikut (BNPB, 2012):

1. Perumusan dan penetapan kebijakan penanggulangan bencana dan penanganan pengungsi dengan bertindak cepat dan tepat, efektif dan efisien.
2. Pengoordinasian pelaksanaan kegiatan penanggulangan bencana secara terencana, terpadu dan menyeluruh.

Berdasarkan hasil penelitian Ramadhan (2017), selama ini proses pendataan kebutuhan korban bencana alam masih menggunakan penulisan pada kertas serta memungkinkan terjadinya kesalahan, lalu belum adanya sistem yang dibuat secara online sehingga mobilitasnya terbatas dalam menyajikan informasi. Permasalahan juga terjadi dalam proses pendistribusian bantuan logistik dari pihak BPBD ke posko-posko bencana alam yang terkadang kurang merata.

Untuk mengatasi masalah-masalah yang sudah dijelaskan sebelumnya, sehingga dibangunlah Sistem Informasi Logistik Kebencanaan yang merupakan sistem informasi berbasis website yang dilengkapi dengan modem satelit VSAT Internet Satelit dengan fokus utama dapat menjangkau daerah yang sulit koneksi jaringan internet. Sistem Informasi Logistik Kebencanaan dapat 
membantu memonitoring pendistribusian barang bantuan, dan menghemat waktu dalam penyampaian bantuan logistik sampai ke posko bencana. Selain itu sistem yang dibangun juga dibantu dengan layanan Google Maps API guna memberikan layanan peta digital untuk keperluan khusus.

Adapun tujuan yang ingin dicapai dalam penelitian adalah membantu menghasilkan informasi yang diharapkan berguna untuk membantu petugas dalam hal supply dan distribusi bantuan logistik, membantu memonitoring persediaan bantuan logistik di gudang, membantu dalam melakukan pelaporan data bantuan logistik.

\section{METODE PENELITIAN}

Metode penelitian yang digunakan adalah SDLC (System Development Life Cycle) dengan menggunakan metode pengembangan Sistem Informasi Prototyping yang akan dilakukan adalah sebagai berikut seperti terlihat pada Gambar 1:

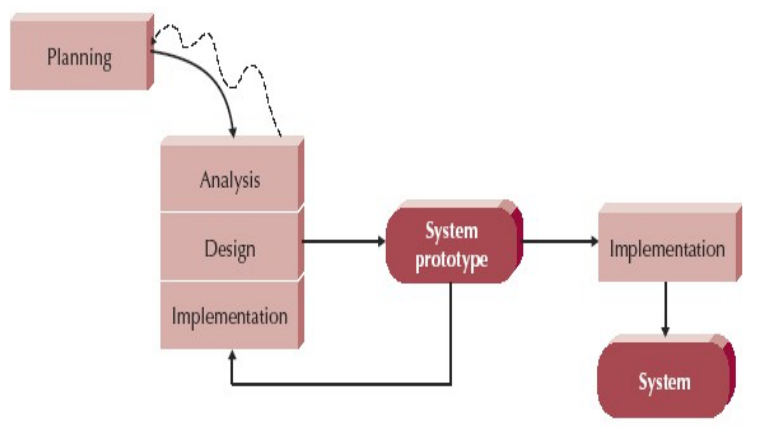

Gambar 1. Metode Penelitian (Prototype)

Tahap penelitian dilakukan dari mulai perencanaan sistem, analisis sistem, serta desain sistem.

\section{Perencanaan Kebutuhan Sistem}

Identifikasi kebutuhan sistem dilakukan dengan melakukan observasi ke Badan Penanggulangan Bencana Daerah Jawa Barat. Serta dilakukan studi literatur untuk mendapatkan teori atau konsep, model maupun komponen yang relevan dengan masalah penelitian beserta metodologinya. Tahap ini dilakukan untuk mendapatkan informasi tentang komponen-komponen kebutuhan sistem yang perlu dirumuskan agar dapat diperoleh gambaran variabel yang diperlukan dalam penelitian ini.

\footnotetext{
Analisis Sistem

Analisis sistem dilakukan dengan pendekatan mempelajari seluruh fungsi dan cara
}

kerja dari setiap komponen proses bisnis oleh BPBD Provinsi Jawa Barat dan disinergikan menjadi solusi yang tepat dan sesuai dengan kondisi dan kebutuhan dari user. Dengan metode analisis tersebut dapat diketahui secara pasti kinerja dari setiap fungsi yang dibutuhkan untuk perancangan sistem informasi bantuan logistik yang akan dibangun.

\section{Desain Sistem}

Tujuan akhir dari desain sistem ini adalah menghasilkan rancangan yang memenuhi kebutuhan yang ditentukan. Desain sistem memiliki 3 tahapan yaitu pemodelan proses, pemodelan data dan desain interface.

\section{Implementasi}

Testing dan Maintenance tidak dilakukan pada penelitian ini. Karena penelitian ini dilakukan hanya sampai perancangan

\section{HASIL DAN PEMBAHASAN \\ Evaluasi Sistem yang Sedang Berjalan}

Selama ini proses pendataan kebutuhan korban bencana alam masih menggunakan penulisan pada kertas sehingga dalam mengelola data bantuan logistic ke korban bencana alam masih kurang efektif dan efisien, lalu belum adanya sistem yang dibuat secara online menyebabkan terbatasnya mobilitas dalam menyajikan informasi. Proses pengolahan data serta pembuatan laporan pun masih menggunakan aplikasi lembar kerja sehingga pada pengerjaannya menyebabkan keterlambatan dan memungkinkan terjadinya kesalahan.

\section{Analisis Sistem}

Proses bisnis yang terjadi saat ini, para petugas melakukan aktivitas logistik kebencanaan dimulai dari pendaataan kebutuhan bantuan logisitk kebencanaan hingga pada tahap pelaporan. Pada analisis proses bisnis digunakan analisis rantai nilai dari Porter (Barnes, 2001). Rantai nilai Porter diadaptasi untuk menganalisis aktivitas spesifik dari sistem infomasi logistik kebencanaan sehingga dapat diketahui aktivitas utama dan aktivitas pendukungnya dengan tujuan akhirnya mendapatkan proses bisnis yang lebih efisien. Rantai nilai poter dari Sistem Informasi Logistik Kebencanaan dapat dilihat pada Gambar 2 berikut: 


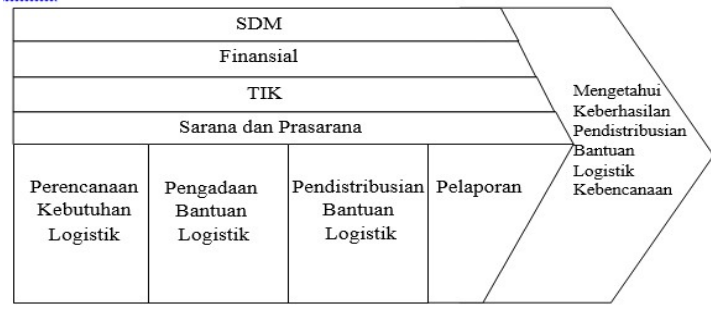

Gambar 2. Rantai Nilai Porter

Rantai nilai pada gambar 2 memiliki jenis aktivitas sebagai berikut:

\section{Aktivitas Utama}

1. Perencanaan Kebutuhan Bantuan Logistik

Proses perencanaan kebutuhan merupakan langkah awal untuk mengetahui apa saja yang dibutuhkan, siapa yang membutuhkan, dimana, kapan dan bagaimana cara menyampaikan kebutuhannya. Perencanaan kebutuhan ini membutuhkan ketelitian dan keterampilan serta mengetahui secara pasti kondisi korban bencana yang akan ditanggulangi. Tujuan utama dari perencananaan kebutuhan ini adalah untuk mengetahui seberapa banyak bantuan logistik dan peralatan yang dibutuhkan.

2. Pengadaan Bantuan Logistik

Proses pengadaan bantuan logistik dimulai dari pencatatan kategori logistik atau peralatan yang diterima, darimana dan kapan bantuan diterima, jenis bantuan yang diterima, jumlah bantuan serta permintaan untuk siapa bantuan ini ditujukan. Pada tahapan ini juga akan dilakukan validasi data barang bantuan logistik dan apabila ada data yang tidak sesuai dan bantuan logistik yang diterima tidak layak maka akan dilakukan penghapusan data bantuan logistik. Sedangkan bantuan yang layak untuk disalurkan akan disimpan terlebih dahulu di gudang.

3. Pendistribusian Bantuan Logistik

Berdasarkan data kebutuhan maka disusunlah perencanaan pendistribusian logistik dan peralatan bantuan kebencanaan disertai data mendukung yaitu didasarkan kepada permintaan atau kondisi darurat dan mendapatkan persetujuan dari pihak yang berwenang. Selanjutkan akan dilakukan pengangkutan bantuan logistik ke posko bencana. Pada saat penerimaan bantuan logistik kebencanaan dilakukan verifikasi data terlebih dahulu dengan bantuan logistik.

4. Pelaporan

Seluruh proses pengelolaan dan pendistribusian bantuan logistik kebencanaan yang telah dilaksanakan harus dibuat laporan pertanggung jawaban.

\section{Aktivitas Pendukung}

1. Sumber Daya Manusia (SDM)

Sumber Daya Manusia berfungsi sebagai penunjang baik dalam kegiatan fisik maupun analisis pengelolaan dan pendistribusian bantuan logistik kebencanaan.

2. Teknologi Informasi dan Komunikasi

Penggunaan teknologi informasi dan komunikasi akan dapat dilakukan perbaikan secara signifikan dalam akses pengolahan data barang bantuan logistik kebencanaan secara akurat baik lokasi maupun waktu.

3. Finansial

Biaya transportasi terjadi karena penggunaan tenaga sopir (driver labor), konsumsi bahan bakar minyak (fuel), pemeliharaan kendaraan, modal yang diinvestasikan dalam kendaraan dan peralatan, penjagaan barang bantuan logistik di gudang, dan kegiatan administrasi.

4. Sarana dan Prasarana

Sarana dan Prasarana merupakan salah satu penunjang atau pendukung keberhasilan dalam proses pengelolaan dan pendistribusian bantuan logistik kebencanaan

Hasil yang didapatkan dari aktivitas utama dan aktivitas pendukung dari proses bisnis yang sedang berjalan di Badan Penanggulangan Bencana Daerah Jawa Barat adalah dapat mengetahui keberhasilan pendistribusian bantuan logistik kebencanaan.

Untuk menggambarkan proses bisnis yang ada digunakan Business Process Modeling Notation (BPMN) (Stephen, 2011). Sebagai contoh adapun kegiatan yang terjadi dalam Sistem Informasi Logistik Kebencanaan Studi Kasus: Badan Penanggulangan Bencana Daerah (Jawa Barat) digambarkan pada Gambar 3. 


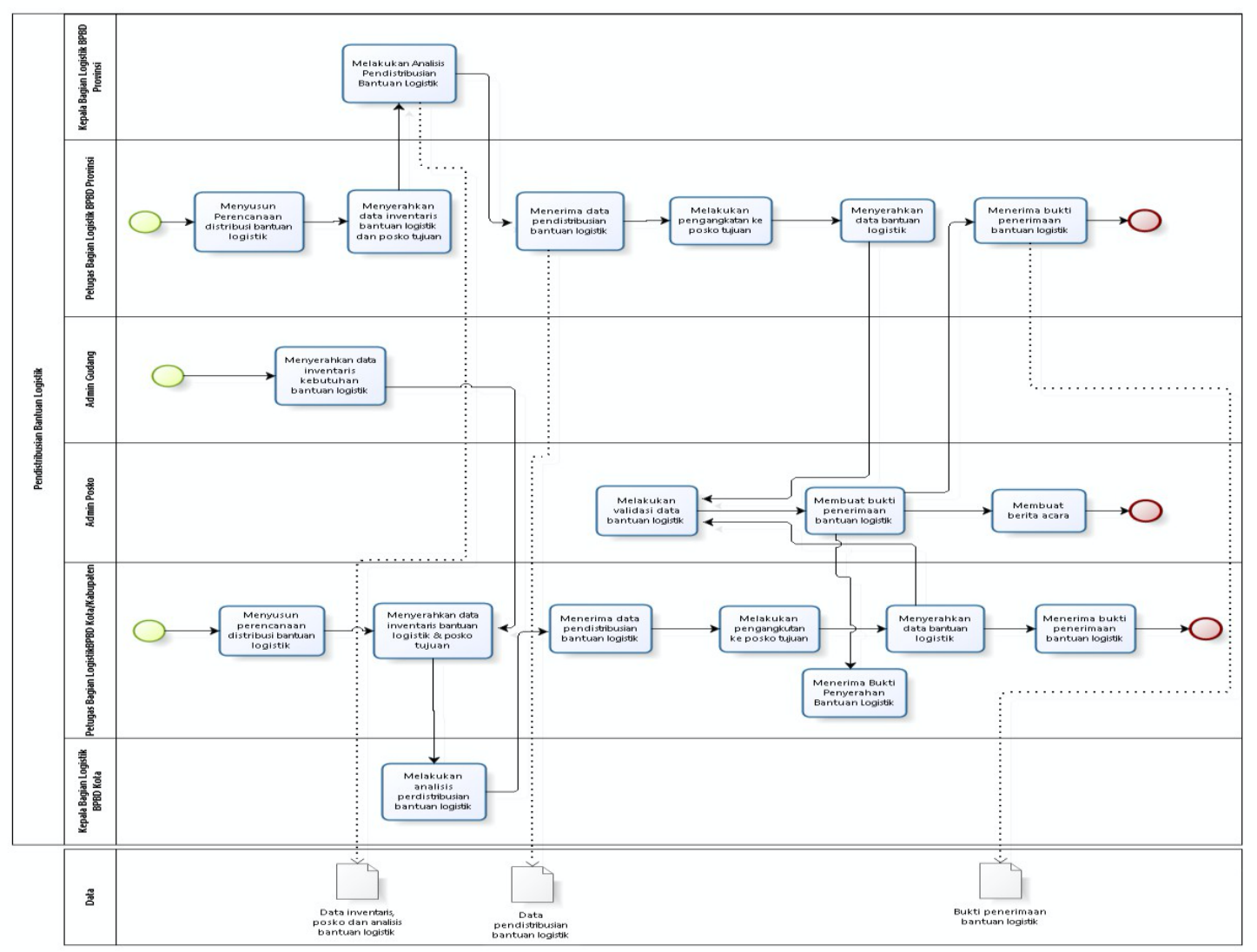

Gambar 3. Proses Pendistribusian Bantuan Logistik

Keterangan:

Pada proses pendistribusian bantuan logistik Petugas Bagian Logistik BPBD Kota/Kabupaten menyerahkan data bantuan logistik kepada Petugas Posko berdasarkan hasil analisis pendistribusian oleh Kepala Bagian Logistik BPBD Provinsi. Selanjutnya petugas posko melakukan validasi data terhadap bantuan logistik. Jika sudah sesuai petugas posko akan membaut berita acara penerimaan bantuan logistik dan menyerahkan kepada Petugas Bagian Logistik BPBD Kota/Kabupaten.

\section{Perancangan Sistem}

Perancangan sistem yang akan dirancang dapat digambarkan pada Usecase Diagram pada gambar 4 dibawah ini. Terdapat 7 aktor yang terlibat serta terdapat fitur-fitur berikut ini guna menyesuaikan dengan fungsi kerja setiap aktornya. Fitur-fiturnya yaitu Login, Kelola User, Kelola Barang, Kelola Daerah, Kelola Posko, Kelola Bencana, Kelola Kebutuhan, Kelola Distribusi, Kelola Laporan, Logout

Gambar 4 merupakan use case dari sistem yang akan dirancang:

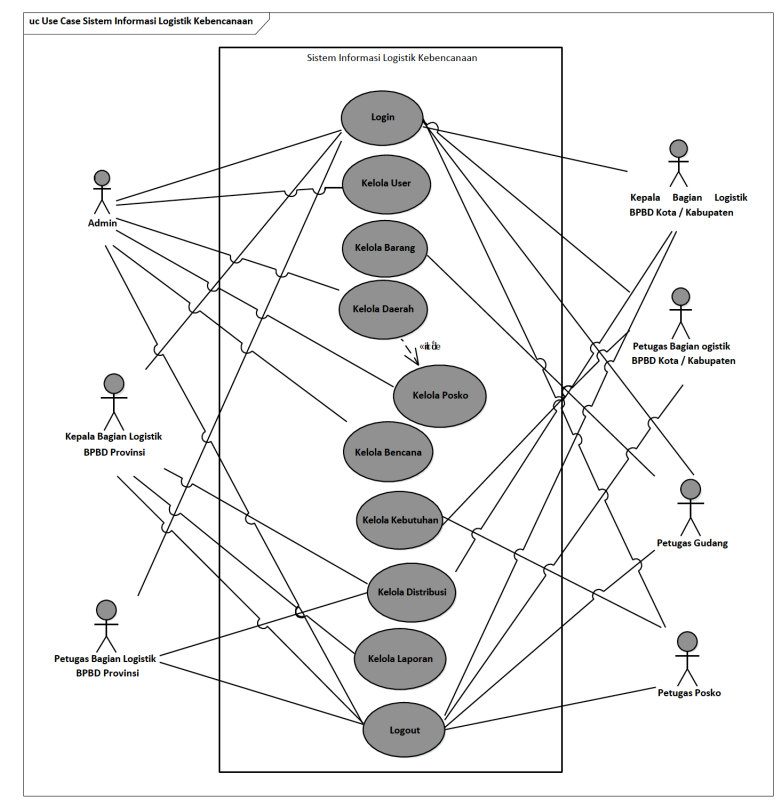

Gambar 4. Usecase Diagram

Pada usecase diagram sistem ini terdapat 7 aktor diantaranya: Admin, Kepala Bagian Logistik BPBD Provinsi Jawa Barat, Petugas Bagian Logistik BPBD Provinsi Jawa Barat, Kepala Bagian Logistik BPBD Kota/Kabupaten, Petugas 
Bagian Logistik BPBD Kota/Kabupaten, Petugas Gudang, dan Petugas Posko

Untuk class diagram dibawah ini sistem. Terdapat 7 kelas yaitu: Login, Barang, Daerah, Posko, Bencana, Kebutuhan dan Distribusi

menjelaskan hubungan antara tiap kelasnya dengan

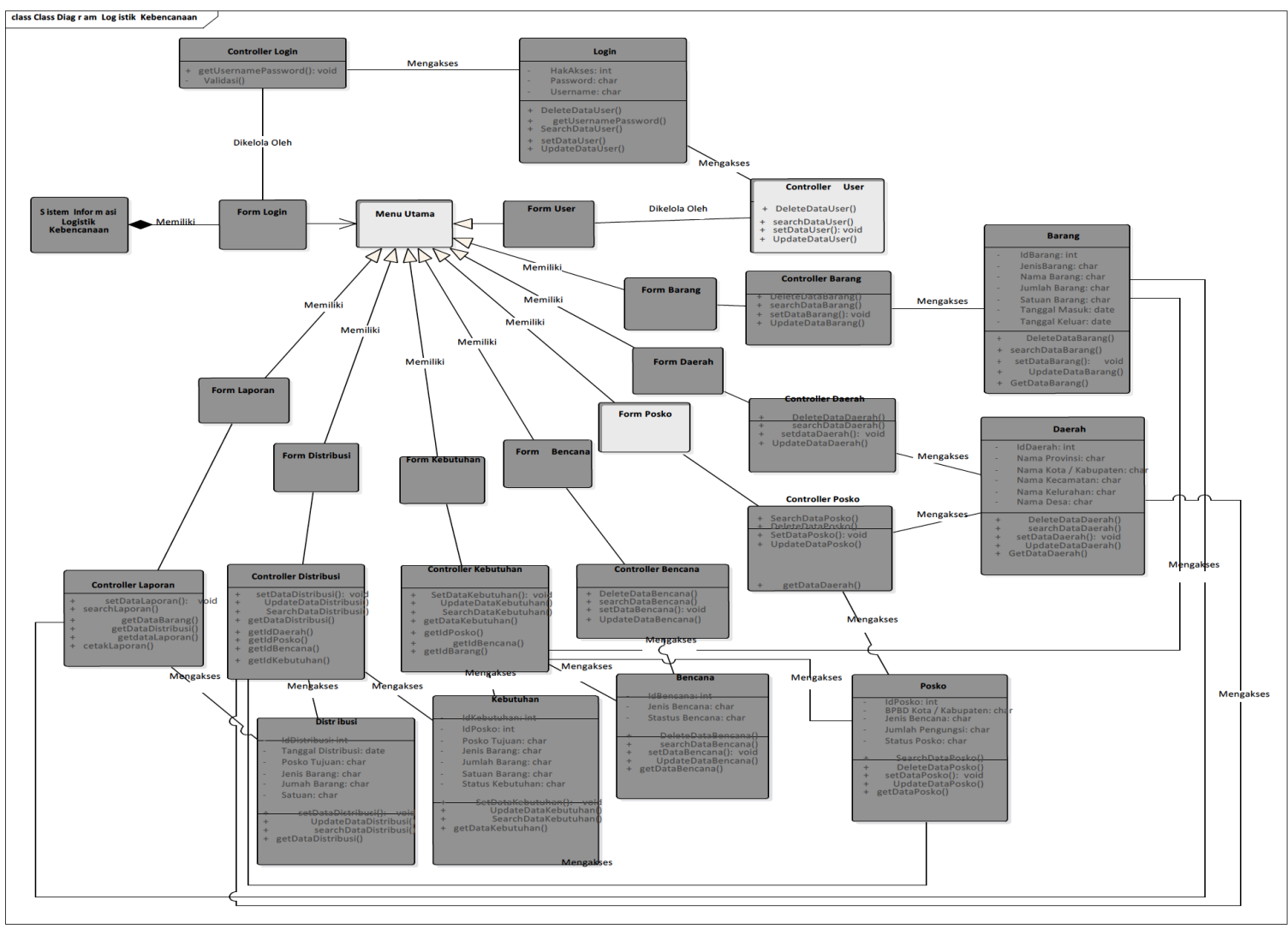

Gambar 5. Class Diagram

\section{Perancangan Halaman Utama}

Perancangan halaman utama sistem ditunjukkan pada Gambar 6 berikut:

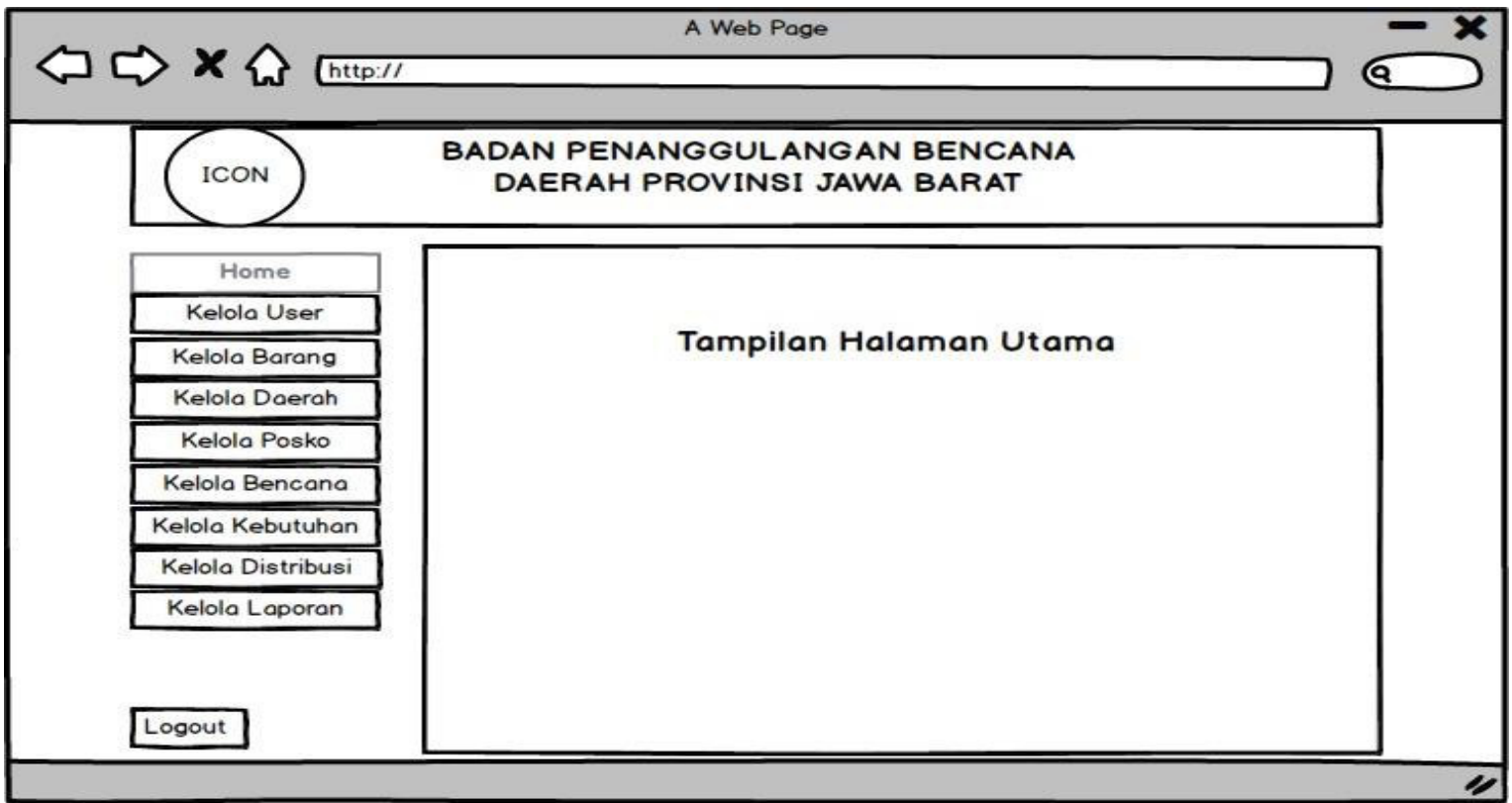

Gambar 6. Rancangan Halaman Utama 


\section{KESIMPULAN}

Simpulan dari penelitian rancangan Sistem Informasi Logistik Kebencanaan Studi Kasus: Badan Penanggulangan Bencana Daerah Jawa Barat yang dilakukan adalah telah terdefinisi proses bisnis BPBD Provinsi jawa Barat yang selama ini berjalan dan terdapat peluang untuk merancang sistem informasi yang berhubungan dengan pengelolaan dan pendistribusian bantuan logistik kebencanaan. Rancangan sistem informasi logistik kebencanaan yang dihasilkan didasari dari proses bisnis yang berjalan serta analisis kebutuhan user yang dapat memberikan kontribusi berupa arsitektur sistem informasi yang dapat dijadikan arahan merealisasikan aplikasi dengan menerapkan rancangan teknologi informasi. Pada tahapan analisis pemodelan yang digunakan menggunakan BPMN, sedangkan pada tahapan perancangan menggunakan UML.

\section{UCAPAN TERIMA KASIH}

Penulis mengucapkan terima kasih kepada Politeknik Pos Indonesia dan Dosen Pembimbing yang telah memberi dukungan terhadap penelitian ini.

\section{DAFTAR PUSTAKA}

Barnes, D. (2001). Understanding Business

Processes. London: The Open University.

Dwiantara, L. dan Sumarto, R. H. (2004). Manajemen Logistik. Jakarta: PT. Grasindo.

Oetomo, B. S. (2002). Perencanaan dan Pengembangan Sistem Informasi. Yogyakarta: Penerbit Andi.

Ramadhan, D., dan Hasugian, L. P. (2017). Sistem informasi manajemen bantuan logistik bencana alam. Prosiding Saintiks FTIK UNIKOM. pp. III.25-III.32

Rinawati, D. I., Sari, D. P., Priatamphatie, F. \& Fahrudin. (2018). Rancang bangun sistem informasi bantuan logistic bencana studi kasus pada BPBD kabupaten magelang. J@ti Undip: Jurnal Teknik Industri, 13 (1), 51-60.

Stephen A., White, S. A. \& Bock, C. (2011). BPMN 2.0 Handbook Second Edition: Methods, Concepts, Case Studies and Standards in Business Process Management Notation. Florida: Future Strategies Inc.
Tim BNPB. (2012). Pengelolaan bantuan logistik pada status keadaan darurat bencana. 